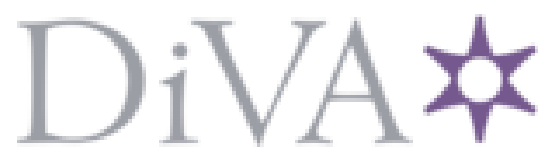

http://www.diva-portal.org

\title{
Postprint
}

This is the accepted version of a paper published in Energy Conversion and Management. This paper has been peer-reviewed but does not include the final publisher proof-corrections or journal pagination.

Citation for the original published paper (version of record):

Campana, P., Li, H., Zhang, J., Liu, J., Yan, J. (2015)

Economic optimization of photovoltaic water pumping systems for irrigation.

Energy Conversion and Management, 95: 32-41

http://dx.doi.org/10.1016/j.enconman.2015.01.066

Access to the published version may require subscription.

N.B. When citing this work, cite the original published paper.

Permanent link to this version:

http://urn.kb.se/resolve?urn=urn:nbn:se:mdh:diva-27650 
1 Title: Economic optimization of photovoltaic water pumping systems for irrigation

2

3

4

5

6

7

8

9

10

11

12

13

14

15

16

17

18

19

20

21

22

Authors: P.E. Campana ${ }^{1}$, H.Li' ${ }^{1}$, J. Zhang ${ }^{2}$, R. Zhang ${ }^{3}$, J. Liu ${ }^{2}$, J. Yan ${ }^{1,4}$

${ }^{1}$ School of Business, Society \& Engineering, Mälardalen University, SE-72123

Västerås, Sweden

${ }^{2}$ Institute of water resources and hydropower research, 100038 Beijing, China

${ }^{3}$ Institute of water resources for pastoral areas, 010020, Hohhot, China

${ }^{4}$ School of Chemical Science, KTH Royal Institute of Technology, SE-10044 Stockholm, Sweden

Corresponding author: P.E. Campana

Corresponding author's contact information: (Email) pietro.campana@mdh.se ; (Phone) +46 (0)21 101469 


\section{Economic optimization of photovoltaic water pumping systems for}

\section{irrigation}

\author{
P.E. Campana ${ }^{1}$, H.Li ${ }^{1}$, J. Yan ${ }^{1}$, ${ }^{2}$ J. Zhang ${ }^{3}$, R. Zhang ${ }^{4}$, J. Liu $^{3}$
}

${ }^{1}$ School of Business, Society \& Engineering, Mälardalen University, SE-72123 Västerås,

Sweden

${ }^{2}$ School of Chemical Science, KTH Royal Institute of Technology, SE-10044 Stockholm, Sweden

${ }^{3}$ Institute of water resources and hydropower research, 100038 Beijing, China ${ }^{4}$ Institute of water resources for pastoral areas, 010020, Hohhot, China

\section{Abstract}

Photovoltaic water pumping technology is considered as a sustainable and economical solution to provide water for irrigation, which can halt grassland degradation and promote farmland conservation in China. The appropriate design and operation significantly depend on the available solar irradiation, crop water demand, water resources and the corresponding benefit from the crop sale. In this work, a novel optimization procedure is proposed, which takes into consideration not only the availability of groundwater resources and the effect of water supply on crop yield, but also the investment cost of photovoltaic water pumping system and the revenue from crop sale. A simulation model, which combines the dynamics of photovoltaic water pumping system, groundwater level, water supply, crop water demand and crop yield was validated against the measured data, is employed during the optimization. 
To prove the effectiveness of the new optimization approach, it has been applied to an existing photovoltaic water pumping system. Results show that the optimal configuration can guarantee continuous operations and lead to a substantial reduction of photovoltaic array size and consequently of the investment capital cost and the payback period. Sensitivity studies have been conducted to investigate the impacts of the prices of photovoltaic modules and forage on the optimization. Results show that the water resource is a determinant factor.

Keywords: Photovoltaic water pumping system, irrigation, grassland desertification, field validation, optimization.

\section{Introduction}

Desertification, defined as land degradation resulting from both climatic-natural variations and human activities, is one of the most crucial worldwide environmental problems affecting food security, water security, eco-security, socioeconomic stability and sustainable development [1]. Photovoltaic water pumping (PVWP) systems, which can provide water for irrigation, have been considered a sustainable and economical solution to curb the progress of desertification [2].

There have been many studies regarding PVWP systems. For example, Bouzidi et al. [3] analysed the performances of such a system installed in an isolated site in the south of Algeria estimating the amount of water that could be supplied under different solar radiation conditions; similarly, Hrayshat and Al-Soud [4] studied the potential application of PVWP systems in Jordan; Bouzidi [5] compared PVWP systems with wind power water pumping (WPWP) systems to cover drinking water requirements in a specific location in Algeria;

Ghoneim [6] developed a program for modelling each PVWP component to assess the 
performance of PVWP systems in Kuwait; Benghanem et al. [7] studied the effect of pumping head on the performance of PVWP systems using an optimal PV array configuration to drive a direct current (DC) helical pump; Mokeddem et al. [8] investigated the performance of a directly coupled PVWP system; Boutelhig et al. [9] compared two different DC pumps with the scope of selecting the optimal direct coupling configuration for providing water to a farm in Algeria; Hamidat at al. [10] presented the electrical and hydraulic performance of a surface centrifugal pump as a function of the hydraulic head and size of PV array for irrigation purposes in the Sahara region; Senol [11] focused on small and medium-size mobile PVWP applications for watering purposes in Turkey; Glasnovic and Margeta [12] elaborated an optimization model for small PVWP system for irrigation; Pande et al. [13] concluded that in order to achieve a successful design of PVWP system, the water supply and crop water requirements for orchards have to be carefully considered. Due to the extreme dynamic variability of the parameters affecting the functioning of PVWP systems, principally solar radiation, dynamic modelling is an important tool to evaluate their performances [14]. Campana et al. [15] modelled both the PVWP system and the crop water requirements to analyse the match between water demand and water supply. Model validation for both PVWP system and crop water requirement was presented in several works: Amer and Younes [16] validated long term performance of PVWP system using a simple algorithm; Hamidat and Benyoucef [17] validated PVWP system models based on the pump experimentation; Luo and Sophocleous [18] validated the models for assessing crop water requirements using a lysimeter. The technical advantages of a novel control system for achieving an optimal matching between crop water demand and water supply and for interfacing PVWP systems to the grid were analysed by Campana et al. [19]. The positive economic and environmental 
aspects of the proposed novel control system for PVWP applications was studied by Campana et al. [20].

Our effort focuses on the application of PVWP technology for irrigation to combat the grassland degradation and to promote the farmland conservation in rural areas of China. Previously, the estimation of the water demand for irrigation and the assessment of the groundwater resources were carried out by Xu et al. [21]. Yu et al. [22] assessed the most suitable areas for PVWP irrigation system in Qinghai Province and in the entire China. The groundwater resource has been identified as a crucial factor concerning the implementation of PVWP for irrigation [23]. The potential benefit of applying PVWP in the improvement of biodiversity of grassland [24], carbon sequestration [25], and energy and food security [26] were also investigated. A novel business model, which can be applied to integrated PVWP systems for grassland and farmland conservation, was proposed, including environmental cobenefits, agricultural products and social visualization of all benefits [27].

The PVWP technology is a well-developed technology with thousands of installations worldwide. The common approach for optimizing a PVWP system mainly deals with the improvement of effectiveness of various system components with the aim of minimizing the total cost. However, Glasnovic and Margeta [12] pointed out that this approach suffers from the lack of systematic quality and static quality. As a result it doesn't yield optimal results. Therefore, a new optimization method, which integrated all relevant system elements and their characteristics systematically, was developed. The objective function was still to minimize the PV size; whereas, the constraints were defined in a new way, which considered not only the water demand, but also the available water resource. The approach was tested at two areas in Croatia. Smaller PV sizes and thus lower PV costs were achieved. Nevertheless, 
the economic feasibility of PVWP is not solely determined by the investment cost of PVWP, it is also tightly related to the benefit from the crop. Even though the investment cost is linearly proportional to the PVWP size, the relationship between PVWP system size, crop yield and pumped water is nonlinear. Hence, it is essential to include that benefit in the optimization of PVWP systems. To the best knowledge of authors, there hasn't been any work regarding optimizing PVWP with the consideration of crop benefit.

The main objective of this paper is thus to develop a new optimization method taking into account the crop yield response to the supplied water and the revenue from selling the crop. As the price of PV modules follows a trend of decrease while the price of crops follows a country trend of increase, the sensitivity study will also be conducted in order to assess the influences of those prices on the optimization. Different from the work carried out by Glasnovic and Margeta [12] that statistic models were used for the simulation of PV system, pumped water and water demand, the following hourly dynamic models are employed in this paper: PV system, inverter-pumping system, water requirements, groundwater level and crop yield response to water. In addition, the hourly models of PVWP system, crop water demand and ground water level are validated against measurements, giving more accurate results. This paper is organized as follows: section 2 presents the proposed optimization approach; section 3 introduces all the models adopted to describe the operation of a PVWP system and provides the model validation; section 4 shows the results of optimization; and section 5 summarizes the important findings of this work. 


\section{Optimization approach and models description}

Genetic algorithm GA has been used to find the optimal PVWP system size, as well recognized optimization technique [28]. The optimization problem finds the optimal size of PVWP systems for irrigation using one objective function under a prerequisite. The objective function is to maximize the annual profit, given by the balance between annual revenue $R_{a n n}(\$)$, annualized initial capital cost $I C C_{a n n}(\$)$ and annual operation, maintenance and replacement cost $o m r_{a n n}$ (\$). It thus (I) maximizes the crop yield $Y_{a}$ (tonne DM/ ha year) and consequently the annual revenue $R_{a n n}$ and (II) minimizes the PVWP system size and consequently the sum of annualized initial capital cost $I C C_{a n n}$ and the corresponding annual operation, maintenance and replacement cost omrann. The prerequisite is to have zero system failure or ensures the $100 \%$ reliability and sustainability of the PVWP system during the whole irrigation season. The PVWP system failure $f$ is defined as the hourly drawdown $s_{h}(m)$ (induced by the pumping system during the irrigation season) goes below the level of pump $h_{p}(\mathrm{~m})$ (measured from the static water level) or the daily water pumped volume $V_{p, d}\left(\mathrm{~m}^{3}\right)$ is larger than the daily sustainable pumped water volume $V_{s, d}\left(\mathrm{~m}^{3}\right)$. Different from previous optimization works, the following constraints are carefully considered in this work: the hourly decline of the groundwater level $s$ and the daily pumped water limited by the water resource $V_{p, d} . s$ and $V_{p, d}$ dynamically depend on the PVWP system capacity and water resource. If those two constraints are not taken into account in the optimization process, the PVWP system capacity can be oversized resulting in the dry-up of well, the broke-down of the pump, and the failure of sustainable water management. Furthermore, an oversized PVWP system also implies higher initial capital costs. The mathematical formulation of the proposed optimization approach is given by the following set of equations: 
154

155

156

157

158

159

160

161

162

163

164

165

166

167

168

169

170

171

$\max \left(R_{a n n}-I C C_{a n n}-o m r_{a n n}\right)$

$$
\sum f=0\left(f=\{0,1\}, f=1 \text { if } s_{h}>h_{p} \text { and } V_{p, d}>V_{s, d}\right)
$$

The annual revenues $R_{a n n}$ from the forage sale depends on the actual forage yield $Y_{a}$ and the specific forage price $p_{f}(\$ /$ tonne DM) according to the following equation:

$R_{a n n}=Y_{a} p_{f}$

The actual forage yield $Y_{a}$ is a function of the pumped water and thus PVWP system capacity and it has been dynamically calculated according to the procedure described in section 3.4. The specific forage price $p_{f}$ has been assumed equal to $207 \$ /$ tonne DM [29]. The $I C C_{a n n}$ has been calculated from the initial capital cost ICC with the following equation:

$I C C_{a n n}=\operatorname{ICC}\left[\frac{i(1+i)^{n}}{(1+i)^{n}-1}\right]$

Where, $i$ and $n$ are the real interest rate and the project lifetime assumed equal to $6.4 \%$ [30] and 25 years, respectively. The ICC of PVWP systems has been estimated from the capacity according to the data provided by a manufacturer company [31]. The PVWP system and components costs are depicted in Figure 1 as a function of the capacity. The PV modules price has been assumed equal to $1,1.5$ and $2 \$ / W_{p}$ to conduct a sensitivity analysis. The specific inverter and pump costs have been assumed equal to 0.5 and $0.15 \$ / W$, respectively [31]. The project implementation costs have been set equal to $30 \%$ of the PVWP components cost, including cost for design and installation [31]. 


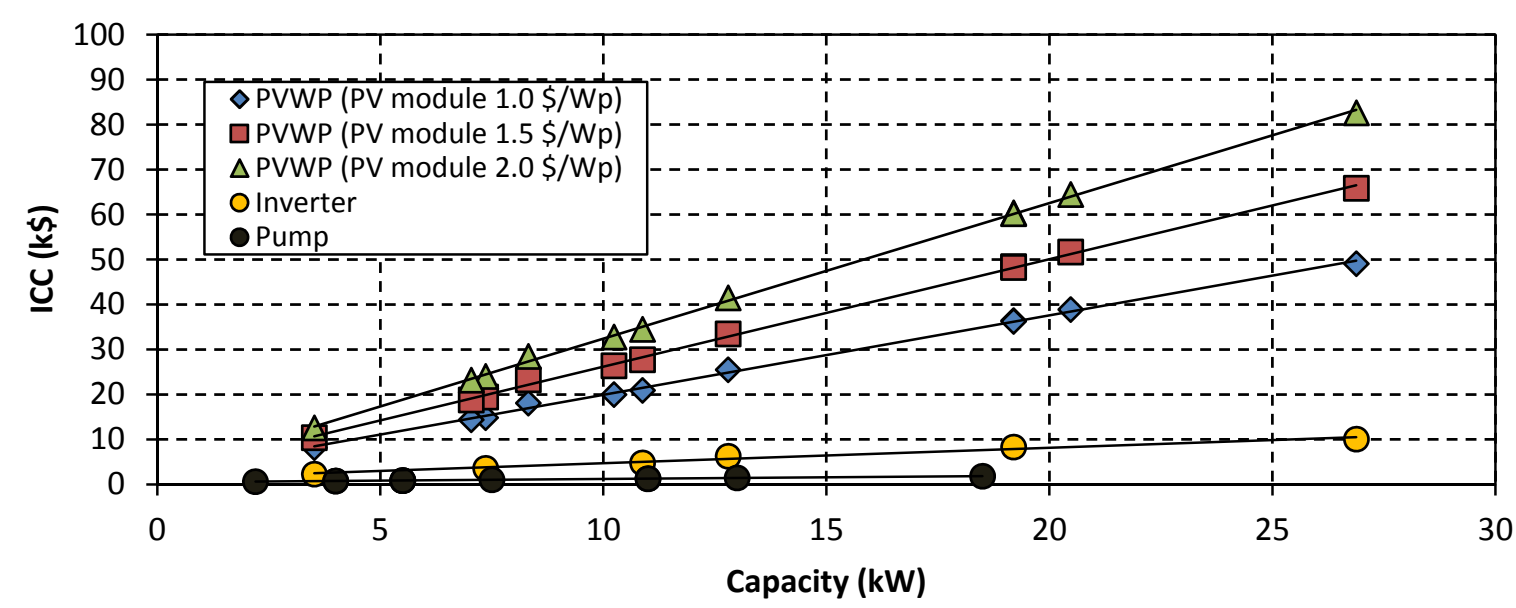

Figure 1: PVWP system initial capital cost as a function of the capacity [31].

174 The annual operation, maintenance and replacement cost $o m r_{a n n}$ has been set to $4 \%$ of the $I C C$, assuming an annual operation and maintenance cost equal to $2 \%$ of the ICC and assuming to replace the pump and the inverter every 8 years. The assessment of the PVWP system

177 profitability has been carried out using the payback period $P B P$ as in previous economic 178 analysis conducted for PVWP systems for irrigation [32]. The optimization is conducted using 179 Solve $\mathrm{XL}$, an add-in for Microsoft Excel that gives the possibility to use $G A$ to solve various 180 optimization problems [33]. The optimization parameters for setting the GA are shown in 181 Table 1.

\begin{tabular}{|l|c|}
\hline Population size & 200 \\
\hline Algorithm & NSGA 2 \\
\hline Crossover rate & $50 \%$ \\
\hline Selector & Crowded tournament \\
\hline Mutation rate & $5 \%$ \\
\hline
\end{tabular}




\begin{tabular}{|l|l|}
\hline Number of generations & 200 \\
\hline
\end{tabular}

184 To optimize the PVWP system, the decision variables include: (I) the PV power peak capacity 185 that has direct effects on the PVWP initial capital costs, volume of pumped water and crop 186 yield and thus annual revenues. It varies in the range of 0 to $3.2 \mathrm{~kW}$; (II) the tilt angle $\beta\left(^{\circ}\right.$ ) and 187 (III) the azimuth angle $\gamma\left({ }^{\circ}\right)$ that have direct effects on the harvested solar irradiation and thus 188 indirectly on the PVWP system size. $\beta$ and $\gamma$ vary in the range of $0^{\circ}$ to $50^{\circ}$ and $-30^{\circ}$ to $30^{\circ}$, 189 respectively. The pumping system capacity has not been considered as decision variable but chosen on the basis of the PVWP system size. Three different pumps capacities and their 191 relative operating curves have been considered: $1.1 \mathrm{~kW}, 1.5 \mathrm{~kW}$ and $3.2 \mathrm{~kW}$, respectively. If the optimal PV size exceeds the pump capacity $30 \%$, then the upper pump capacity is selected.

The optimization problem finds the optimal solution in terms of tilt angle, azimuth angle and PV power peak capacity that allows to increase the profit without violating the groundwater level constraint.

It has to be emphasized that the optimization conducted by Glasnovic and Margeta [12] was based on decade time step, which cannot reflect the intrinsic dynamic performances of PV power, pumped water, induced drawdown. In this work, the optimization is based on hourly dynamic models of the crop water requirements, pumped water and groundwater response to pumping and crop yield. The optimization process is led using hourly data for the crop 201 irrigation season occurring from the beginning of April to the end of July [21]. 


\section{Modelling the PVWP system}

The dynamic simulation of a PVWP system needs the models of photovoltaic array, inverter and water pump, crop water demand, groundwater response to pumping and crop growth as shown in Figure 2. The PV array model calculates the conversion of solar radiation into power. The inverter-pump model simulates the behaviour of the power conditioning system and pump according to the power generated by the PV array. The crop water demand model is used to assess the crop water requirements both for designing and simulation purposes. The groundwater supply and crop growth models simulate the effect of water pumping on the groundwater level and crop yield, respectively. To ensure a correct and continuous operation of the system and for a sustainable exploitation of the groundwater, the groundwater resources have to be more abundant than the water demand. The description of the hydraulic head model has been omitted in this work since it relies on the common laws of hydraulic. Alfalfa (Medicago Sativa) is used as reference crop in this paper since it is the growing crop at the PVWP pilot site tested in this paper. 


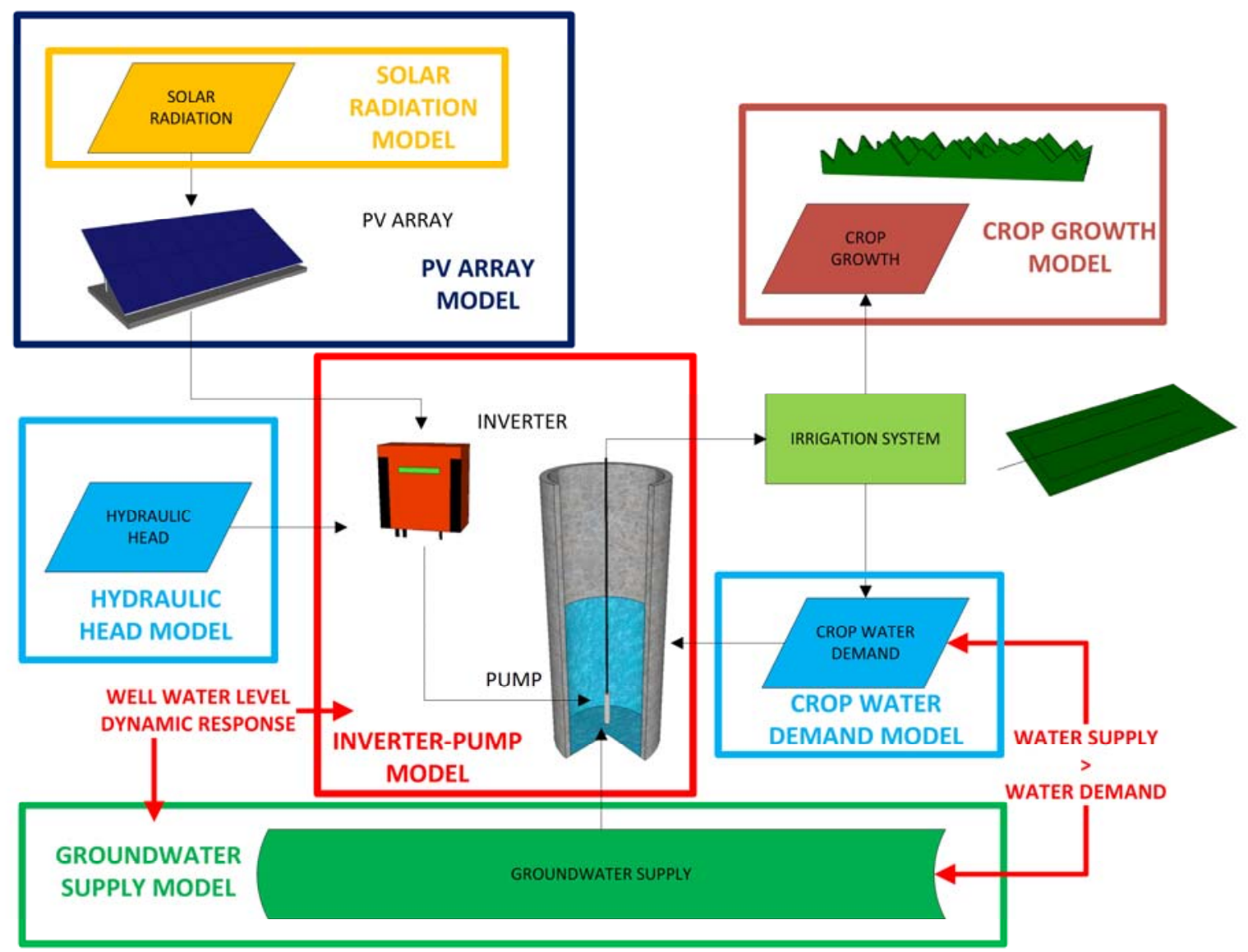

Figure 2: Overview of the modelling blocks of an integrated PVWP system.

\subsection{Photovoltaic array}

219 Photovoltaic (PV) modules convert the total solar radiation received onto the tilted surface

220 into electricity. The total solar radiation $G_{g, t}(\mathrm{~W})$ depends on the horizontal radiation, surface

221 orientation and it is given by three different contributions: beam radiation $G_{b, t}(\mathrm{~W})$, diffuse radiation

$222 G_{d, t}(W)$ and reflected radiation $G_{r, t}(W)$ :

$223 G_{g, t}=G_{b, t}+G_{d, t}+G_{r, t}$

224 The beam component of the global tilted radiation can be calculated from the horizontal

225 radiation through the following equation presented in Duffie et al. [34]: 
$226 \quad G_{b, t}=\frac{G_{g, h}-G_{d, h}}{\cos (90-\alpha)} \cos (\theta)$

227 Where, $G_{g, h}$ is the global horizontal radiation (W), $G_{d, h}$ is the diffuse horizontal radiation (W), $228 \alpha$ is the solar altitude $\left({ }^{\circ}\right)$ and $\theta$ is the angle of incidence $\left({ }^{\circ}\right)$. The angle of incidence $\theta$, function 229 of the declination angle $\delta\left({ }^{\circ}\right)$, latitude $\varphi\left({ }^{\circ}\right)$, tilt angle $\beta\left({ }^{\circ}\right)$, azimuth angle $\psi\left({ }^{\circ}\right)$ and hour angle $230 \omega$, has been computed according to the procedure described in Duffie and Beckman [34]. The 231 diffuse component is given by:

232

$$
G_{d, t}=G_{d, h} \frac{1+\cos (\beta)}{2}
$$

233 The ground reflected radiation is given by the following relation:

$$
G_{r, t}=\rho_{g} G_{d, h} \frac{1-\cos (\beta)}{2}
$$

Where, $\rho_{g}$ is the ground reflectance. The hourly values of the global horizontal radiation and of the diffuse horizontal radiation have been taken as input for the solar radiation model. The required hourly data of solar radiation were collected from the weather station located nearby the tested PVWP system. According to Duffie and Beckman [34], the hourly power output from the PV array $P_{P V}(\mathrm{~W})$ is given by:

240

$$
P_{P V}=\eta_{P V} A_{P V} G_{g, t}
$$

241 Where, $\eta_{P V}$ is the efficiency of the PV module (\%) and $A_{P V}$ is the PV array area that depends on

242 the PV power peak capacity installed. $\eta_{P V}$ is given by the following equation [34]:

$$
\eta_{P V}=\eta_{P V, S T C}\left[1+\frac{\mu}{\eta_{P V, S T C}}\left(T_{a}-T_{S T C}\right)+\frac{\mu}{\eta_{P V, S T C}} \frac{(N O C T-20)}{800}\left(1-\eta_{P V, S T C}\right) G_{g, t}\right]
$$


244 Where, $\eta_{P V, S T C}$ is the efficiency of the PV module at standard test conditions (STC), $\mu$ is the 245 temperature coefficient of the output power $\left(\% /{ }^{\circ} \mathrm{C}\right), T_{a}$ is the ambient temperature $\left({ }^{\circ} \mathrm{C}\right), T_{\text {STC }}$ 246 is the standard test conditions temperature $\left(25^{\circ} \mathrm{C}\right)$ and $N O C T$ is the nominal operating cell 247 temperature $\left({ }^{\circ} \mathrm{C}\right)$. According to Duffie and Beckman [34], the temperature coefficient of the 248 output power $\mu$ can be approximated to:

$249 \mu \approx \eta_{P V, S T C} \frac{\mu_{V_{o c}}}{V_{m p}}$

250 Where, $\mu_{\text {voc }}\left(\mathrm{V} /{ }^{\circ} \mathrm{C}\right)$ is the open circuit voltage temperature coefficient and $V_{m p}(\mathrm{~V})$ is the voltage 251 at maximum power point. Table 2 summarizes all the characteristic parameters of the PV 252 modules simulated in this paper. 


\begin{tabular}{|l|c|}
\hline$I_{m p}(A)$ & 4.6 \\
\hline$V_{m p}(V)$ & 34.8 \\
\hline$I_{s c}(A)$ & 5.16 \\
\hline$V_{o c}(V)$ & 43.8 \\
\hline Area $\left(m^{2}\right)$ & 1.32 \\
\hline$\eta_{P V, S T C}(\%)$ & 12.56 \\
\hline$\mu_{\text {Voc }}\left(\mathrm{V} /{ }^{\circ} \mathrm{C}\right)$ & -0.147 \\
\hline NOCT $\left({ }^{\circ} \mathrm{C}\right)$ & 45 \\
\hline
\end{tabular}

$274 \quad Q_{o}=Q_{r} \sqrt{\frac{H_{o}}{H_{r}}}$

\subsection{Inverter-water pumping system}

The water pumped by a PVWP system significantly depends on the dynamic variability of the solar radiation, ambient temperature, performances of the inverter and the pumping system. Solar radiation and ambient temperature affect primarily the power output from the PV array whereas the ambient temperature and the supplied power affect the efficiencies of the inverter and pump. The efficiency of the inverter has been taken from an inverter database and set to $95 \%$ [36]. The pump efficiency curve (water flow versus power input for a given head) has been calculated from the standard characteristic pump curve (head versus water flow) according to the following set of equations derived from the affinity laws and compiled by Abella et al. [37]: 
$275 \quad P_{p, o}=\rho g H_{o} \frac{Q_{r}}{\eta_{p}} \sqrt{\frac{H_{o}}{H_{r}}}$

$276 \quad P_{P V}=\frac{P_{p, o}}{\eta_{m, o} \eta_{i n v}}$

277 Where, $Q_{o}\left(\mathrm{~m}^{3} / \mathrm{h}\right)$ is the operational water flow corresponding to the operational hydraulic head $H_{o}(\mathrm{~m}), Q_{r}$ is the reference water flow $\left(\mathrm{m}^{3} / \mathrm{h}\right)$ at the reference hydraulic head $H_{r}(\mathrm{~m})$ from

279 the pump standard characteristic curve, $P_{p, o}$ is the operational pump power (W), $\eta_{m, o}$ is the 280 efficiency of the motor at the corresponding working conditions and $\eta_{\text {inv }}$ is the efficiency of 281 the inverter (\%).

\subsection{Irrigation water requirements}

The assessment of the water demand plays a key role in the design of the PV array, pumping unit and irrigation system. Moreover, the evaluation of the crop water requirements is significant in order to guarantee a sustainable and efficient management of the water resources, since the water demand cannot exceed the available water resources. The water demand for the entire crop cycle is strictly bounded to the climatic conditions of the specific site, especially air humidity, ambient temperature, solar radiation, wind speed and precipitation. The crop water demand and yield response to water is typically determined from the reference evapotranspiration $E T_{0}$. The daily and hourly assessment of the crop water

291 demand has been evaluated using the FAO Penman-Monteith method [38]. The hourly reference evapotranspiration $E T_{0}(\mathrm{~mm} /$ hour$)$ is given by the following relationship:

$E T_{0}=\frac{0.408 \Delta\left(R_{n}-G\right)+\gamma \frac{37}{T_{a}+273} u_{2}\left(e_{s}-e_{a}\right)}{\Delta+\gamma\left(1+0.34 u_{2}\right)}$ 
Where, $R_{n}$ is the net radiation at the grass surface (MJ/m² hour), $G$ is the soil heat flux density $\left(\mathrm{MJ} / \mathrm{m}^{2}\right.$ hour), $T_{a}$ is the mean hourly air temperature $\left({ }^{\circ} \mathrm{C}\right), \Delta$ is the saturation slope of vapor pressure curve at $T_{a}\left(\mathrm{kPa} /{ }^{\circ} \mathrm{C}\right), \gamma$ is the psychrometric constant expressed $\left(\mathrm{kPa} /{ }^{\circ} \mathrm{C}\right), e_{s}$ is saturation vapour pressure $(\mathrm{kPa}), e_{a}$ is the average hourly actual vapour pressure $(\mathrm{kPa})$ and $u_{2}$ is the average hourly wind speed $(\mathrm{m} / \mathrm{s})$. The irrigation water requirements have been assessed from the reference evapotranspiration $E T_{0}$, calculating the evapotranspiration in cultural conditions $E T_{c}$, the effective precipitation $P_{e}$ and taking into account the efficiency of the irrigation system. The procedure to compute the irrigation water requirements is thoroughly described in Campana et al. [15] and in Allen et al. [38].

\subsection{Crop growth model}

To evaluate the benefits of PVWP systems, predicting the crop yield corresponding to the water supply represents a key issue. In 1970s, FAO proposed a relationship between crop yield and water supply to predict the reduction in crop yield. The crop-water production function relates the relative yield reduction to the relative reduction in evapotranspiration and is given by Allen et al. [38]:

$$
\left(1-\frac{Y_{a}}{Y_{m}}\right)=K_{y}\left(1-\frac{E T_{a}}{E T_{c}}\right)
$$

Where, $Y_{a}$ is the actual yield (tonne DM/ha), $Y_{m}$ is the maximum yield (tonne DM/ha), $K_{y}$ is the yield response factor, $E T_{a}$ is the actual evapotranspiration ( $\mathrm{mm} / \mathrm{hour}$ ) and $E T_{c}$ is the evapotranspiration in cultural conditions with no water stress ( $\mathrm{mm} /$ hour). The actual yield $Y_{a}$ represents the crop yield reduction compared to the maximum due to a reduction in the water provided through irrigation. The maximum Alfalfa yield $Y_{m}$ used in the simulations has been assumed equal to 8 tonne DM/ha year as confirmed by a local specialist of the studied area 
[39]. The yield response factor $K_{y}$ simplifies the complex natural procedures that rule the effect

of water deficit on the crop productivity. $K_{y}$ for Alfalfa is equal to 1.1 as given by Allen et al. [38]. The actual evapotranspiration $E T_{a}$ depends on the available water supply to the crop (both through irrigation and rainfall) and on the soil parameters. The soil parameters assumed in this work were taken from a previous work conducted in the same studied area [21]. The procedure adopted to calculate the actual evapotranspiration $E T_{a}$ is thoroughly described in Allen et al. [38]. Several papers have used the crop-water production function for estimating the crop productivity: Garg and Dadhich [40] used and validated the crop yield function for assessing the effect of deficit irrigation on eight different crops in India; Igbadun et al. [41] compared four different crop-water production functions for evaluating the effect of deficit irrigation on maize. It resulted that Equation 16 was the best for simulating the crop yield. In this paper, the crop-water production function has been used as direct method to simulate the crop yield on the basis of the water supplied by the PVWP system. The crop yield simulations together with the crop prices have been used to evaluate the revenues generated by the PVWP system operation in order to identify the optimal point between revenues, costs and constraints.

\subsection{Groundwater supply model}

The modelling of the aquifer response to the PVWP system operation is of significant importance for predicting the drawdown $s$ (the lowering of the water level in the well compared to the static water level) and then the effective dynamic head of the pumping system. During the operation of PVWP system, the drawdown s results in unsteady conditions for most of the time due to the dynamic variation of the power output from the PV array. Typically, groundwater transient modelling is based on Theis equation, which gives the 
$349 \quad s(r, t)=\frac{Q_{0}}{2 \pi T} K_{0}\left(r \sqrt{\frac{i \omega}{D}}\right)$ out by Zhang et al. [45].

\subsection{Model validation}

unsteady distribution of the drawdown $s$ at a radial distance $r$ and at the time $t$ under the following assumptions: (I) homogeneous and isotropic confined aquifer, (II) no source recharging the aquifer, (III) aquifer compressible, (VI) water released instantaneously as the head is lowered and (V) constant pumping flow [42]. The assumption regarding the constant pumping is unrealistic for PVWP system application and make the Theis equation inappropriate for groundwater flow modelling. The analytical solutions of the equations governing groundwater flows assuming inconstant pumping flows were obtained by Ospina et al. [43]. In this work, the method proposed by Rasmussen et al. [44] is used to simulate the drawdown. If the pumped water and the characteristic of the aquifer are known, the following equation calculates the drawdown s:

Where, $r$ is the distance from the pumping well assumed equal to $1 \mathrm{~m}, t$ is the time variable (1h), $Q_{0}$ is the pumping rate $\left(\mathrm{m}^{3} / \mathrm{h}\right), T$ is the aquifer transmissivity $\left(\mathrm{m}^{2} / \mathrm{h}\right), K_{0}$ is the zero-order modified Bessel function, $i$ is the imaginary number, $\omega$ is the pumping frequency (given by the ratio between $2 \pi$ and $p$, the pumping cycle) $(\mathrm{Hz})$ and $D$ is the hydraulic diffusivity $\left(\mathrm{m}^{2} / \mathrm{h}\right)$. The aquifer transmissivity and the hydraulic diffusivity were taken from the pumping tests carried

To obtain the optimal results, it is of great importance to select the models that can simulate the PVWP system accurately and provide correct inputs to the optimization. In the work conducted by Glasnovic and Margeta [12], the models were not carefully validated. In this 
work, measurements have been conducted at a pilot PVWP system and the models used in optimization have been validated against the measurements.

362

363

\subsubsection{Measurements at the pilot PVWP system}

The tested PVWP system is located in the Wulanchabu desert grassland area, Inner Mongolia, China, which latitude, longitude and altitude of the site are $41.32^{\circ} \mathrm{N}, 111.22^{\circ} \mathrm{E}$ and $1590 \mathrm{~m}$ above the mean sea level. It is used to provide water for 1 ha of Alfalfa cultivated field. The main system components and PV array orientation angles are listed in Table 3.

Table 3: PVWP system components and characteristics.

\begin{tabular}{|l|c|}
\hline Number PV modules & 9 \\
\hline PV power $\left(\mathrm{kW}_{\mathrm{p}}\right)$ & 1.44 \\
\hline Pump $(\mathrm{kW})$ & 1.1 (AC centrifugal) \\
\hline Tilt angle $\left(^{\circ}\right)$ & 42 \\
\hline Azimuth $\left(^{\circ}\right)$ & -36 \\
\hline
\end{tabular}

To avoid dry running of the motor-pump, a water level probe is installed on the upper part of the pump. If the water level in the well reaches the probe, the inverter shuts down and makes attempt to restart each 30 minutes. The well is marked out by a static water level of $5 \mathrm{~m}$ below the ground surface. The pump is positioned at the bottom of the well, at $3.5 \mathrm{~m}$ depth from the static water level. The pump safety probe is installed on the top of the pump, at $2.5 \mathrm{~m}$ depth from the static water level. To measure the variation of the well water level, a water pressure probe with data logger is installed at the bottom of the well. The PVWP system has been tested in two different scenarios: recirculation scenario (S1) - the water lifted up by the pumping system was recirculated back into the well; and micro irrigation scenario (S2) - the 
water lifted up from the well is pumped directly into a micro irrigation system located about $150 \mathrm{~m}$ far from the well. S1 has aimed to test the pumping system and to validate the models regarding the PVWP system. The main purpose of S2 was to analyse the effects of pumping on the groundwater level. To measure the water pumped from the well, two flow meters are installed along the pipeline network. All the performed measurements and the corresponding used instruments are listed in Table 4. Figure 3 shows a schematic diagram of the tested PVWP system scenarios together with the instruments used for gathering the operational data.

Table 4: Measurement carried out during the tests and the corresponding instruments and resolutions.

\begin{tabular}{|l|c|c|c|}
\hline Measurements & Instrument & Logging time & Resolution \\
\hline Solar radiation & Pyranometer & 1 hour & $\pm 1 \mathrm{~W} / \mathrm{m}^{2}$ \\
\hline Power & DC/AC power meter & 1 hour & $\pm 1 \mathrm{~W}$ \\
\hline Water flow & Flowmeter & 1 hour & $\pm 0.001 \mathrm{~m}^{3}$ \\
\hline Well water table & Pressure sensor & 1 hour & $\pm 0.02 \mathrm{mwc}$ \\
\hline Evapotranspiration & Weighing lysimeter & 1 hour & $\pm 0.02 \mathrm{~mm}$ \\
\hline
\end{tabular}

The measured data about solar radiation, power output and water flow were used to validate the PVWP system model, in particular the pump efficiency curve (water flow versus power input for a given head). The measurements of the well water level were used to validate the model related to the groundwater level response to pumping. The weighing lysimeter data 


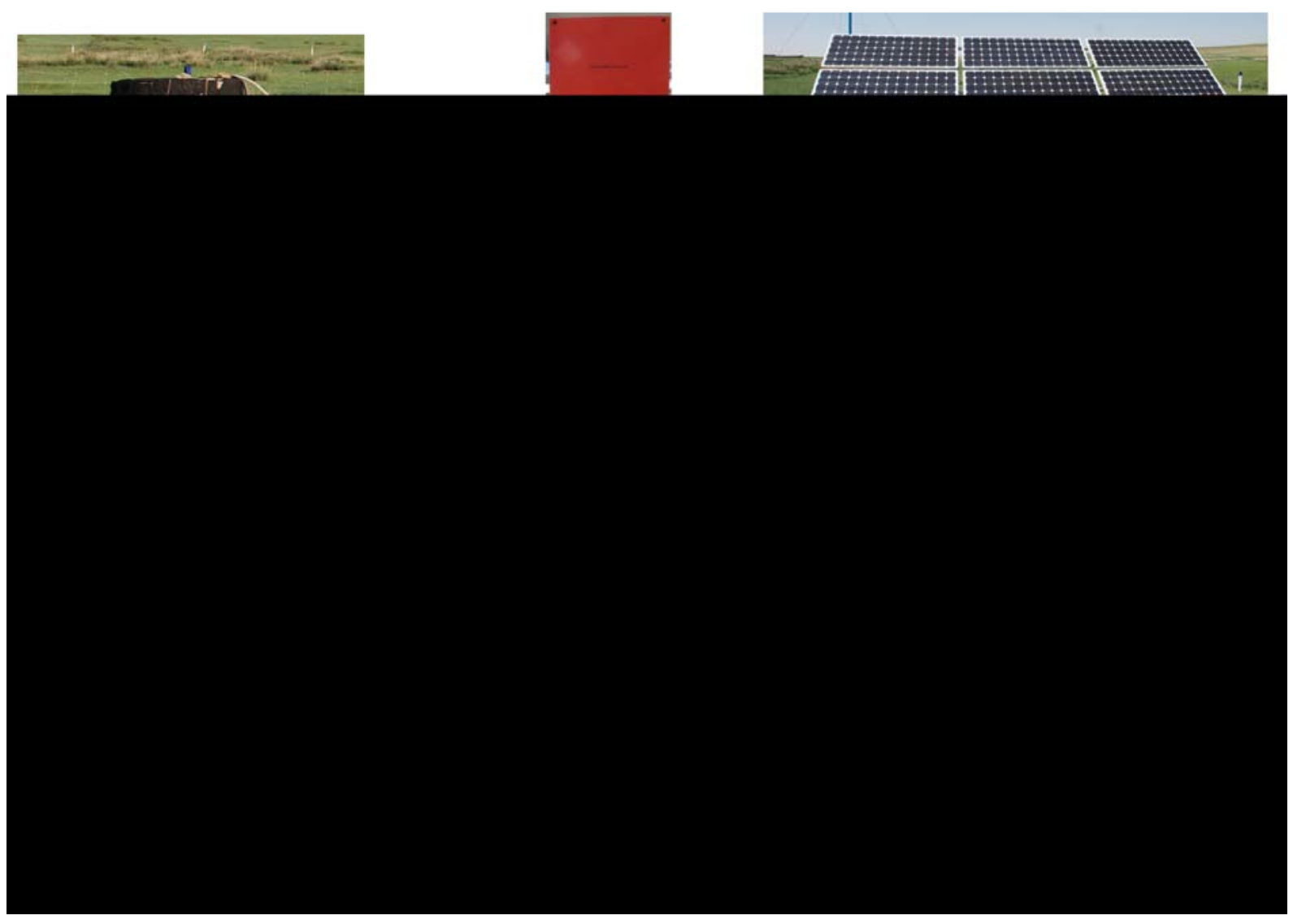

Figure 3: Schematic diagram of the system configurations used during the tests.

It has to be pointed out that the tests carried out in irrigation scenario (S2) aimed to analyse the effects of PVWP system operation on the groundwater level and to introduce the novel optimization procedure for PVWP systems for irrigation.

Figure 4 compares the simulated results and the measured water flow. Good agreement is observed at power inputs lower than $800 \mathrm{~W}$. The discrepancy between modelled data and measured data is higher at higher PV power inputs due to the system configuration: PVWP 
405

406

407

408

409 enough to run the pumping unit.

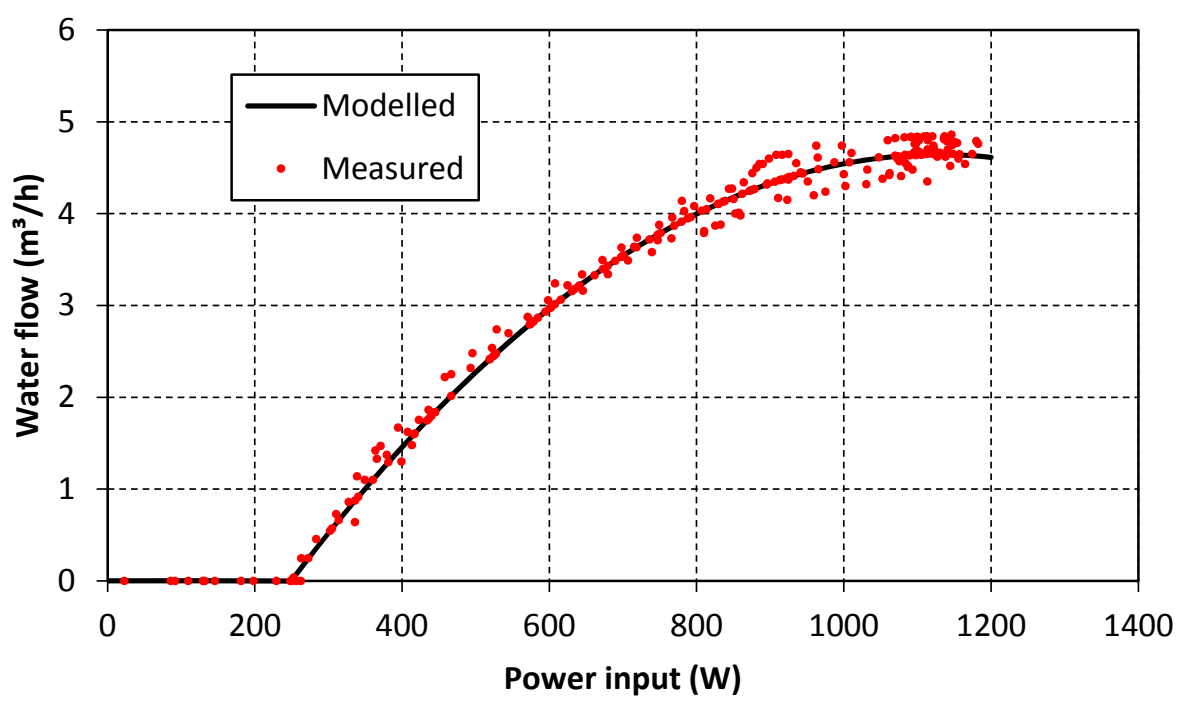

410

Figure 4: Pumping tests in recirculation scenario.

Figure 5 compares the simulated results and the measured data about the reference evapotranspiration. The measured data have been reconciled by the outliers produced during the precipitation events. In general, the calculated results agree well with the measured data. The discrepancies between measured and calculated data are caused by the pressure of wind gusts on the lysimeter, objects on the lysimeter and temperature effects. 


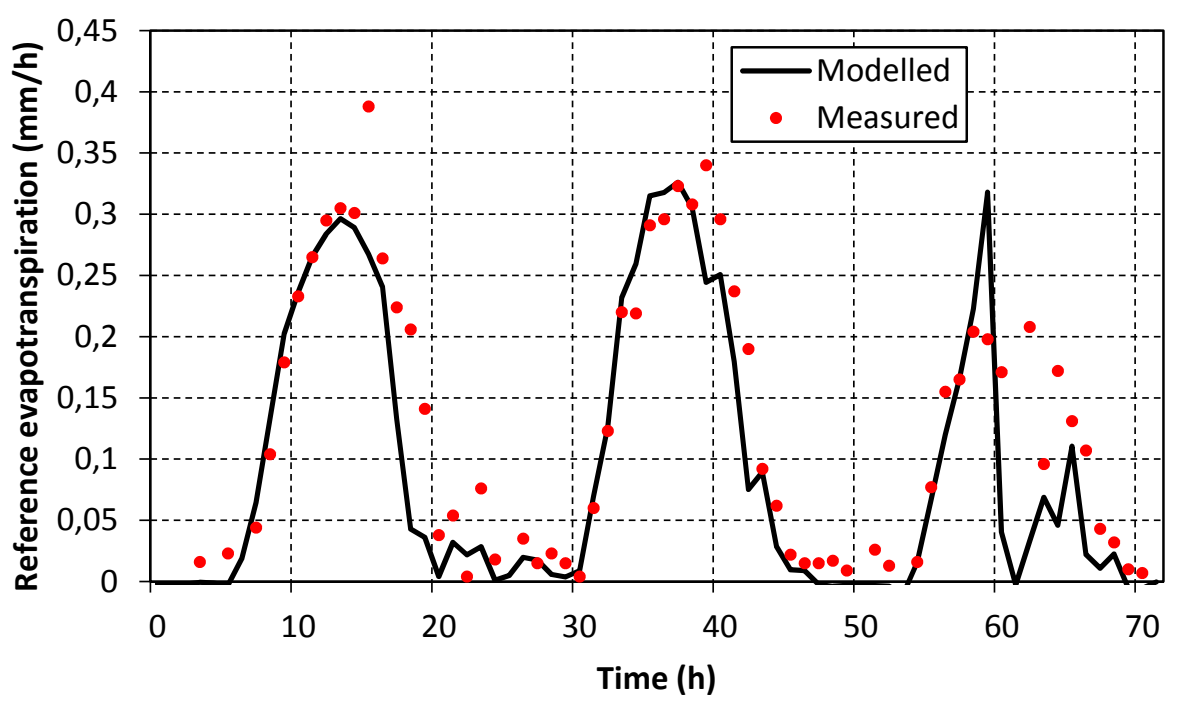

Figure 5: Measured and modelled hourly evapotranspiration data. of the water flow.

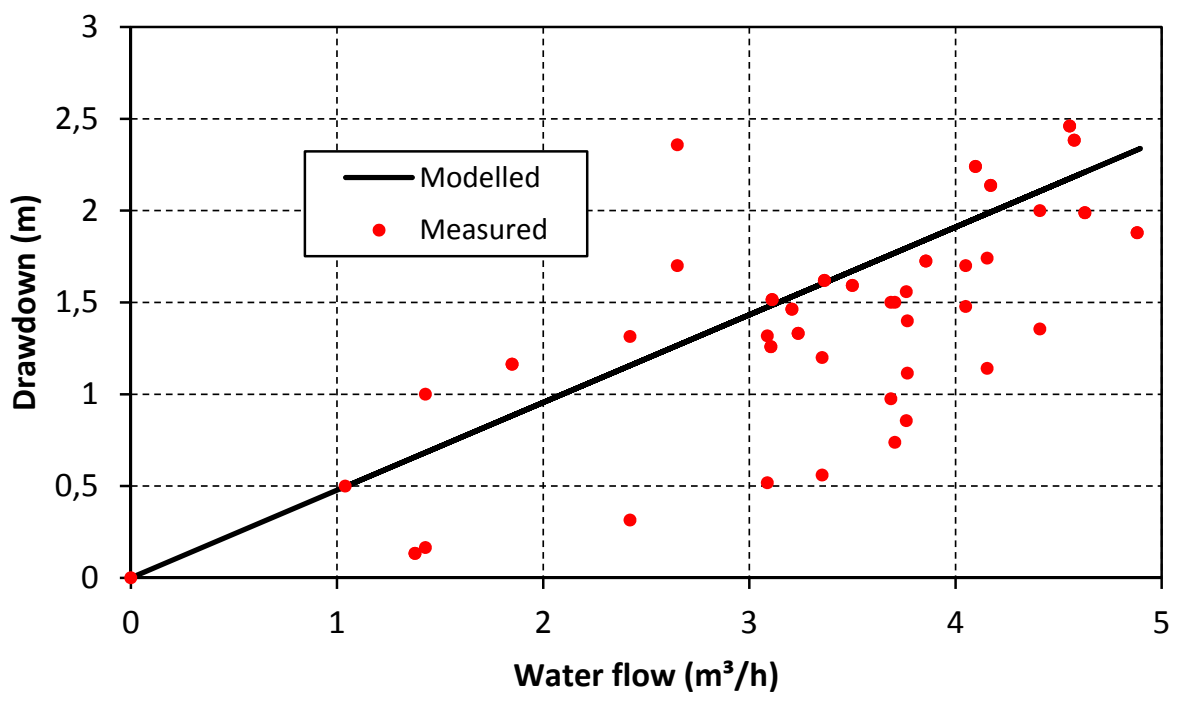

Figure 6: Measured and modelled hourly groundwater level.

424 The discrepancy may be caused by the poor borehole construction technique, inadequate and

425 low accuracy instrumentation and field conditions. Nevertheless, it has to be pointed out that 
the maximum deviation between measured and modelled data at the highest pumping rate is less than $0.5 \mathrm{~m}$. It implies that the model can be considered suitable to describe at least the maximum pumping effect in terms of drawdown. Moreover, it has to be emphasized that the same model showed an excellent agreement with the field measurement data in previous tests carried out by Rasmussen et al. [44] at different aquifers with high accuracy equipment.

\section{Optimization results and discussions}

\subsection{Identified problem}

Figure 7 shows the measured pumped water as a function of the solar radiation and the water level in the well. Since the pumped water by the PVWP system is larger than the recharge rate of the well, the groundwater table declines. Therefore, it implies that the designed PVWP system was oversized. To avoid dry-up conditions, the inverter safety control system stops the pump and the operation of the system is interrupted after $12 \mathrm{pm}$ every half hour. Although there is still abundant solar radiation and thus power from the PV array, the pumped water volume decreases of about half. To overcome the encountered problem, it would have been significant to test the recharge rate of well before the installation of the PVWP system. Moreover, it has to be pointed out that the water availability in the well can notably vary from year to year, especially from wet to dry year, affecting consequently the system design and the irrigable area. 


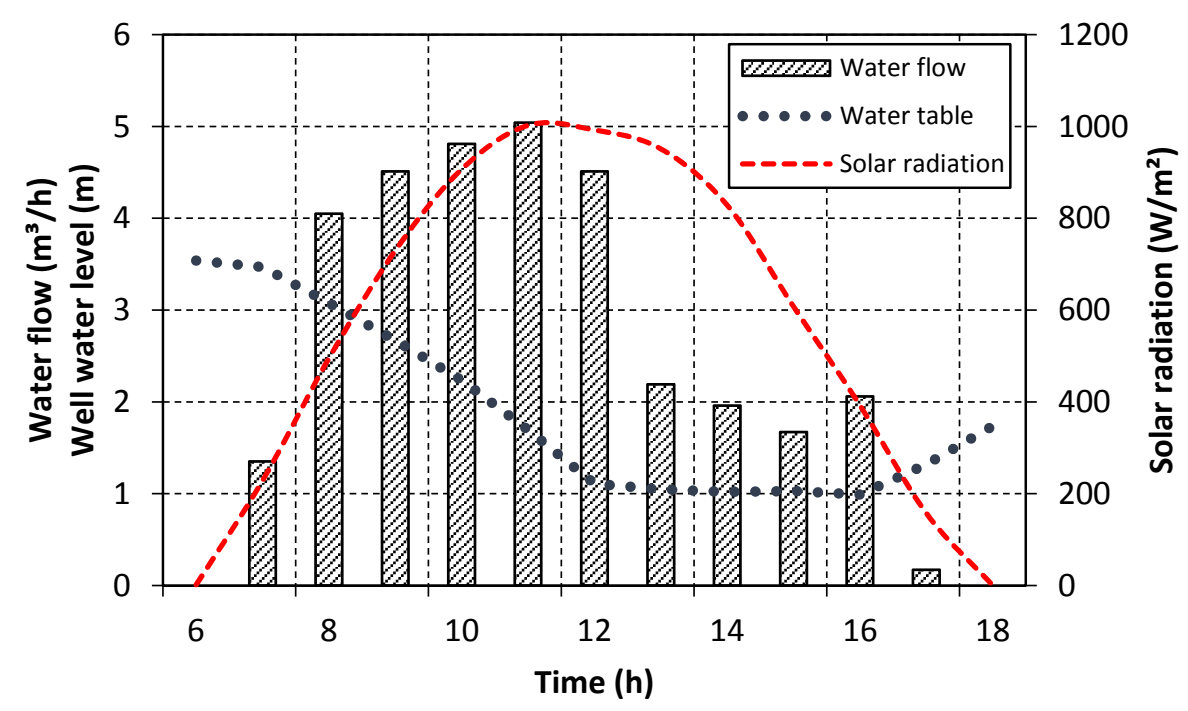

$447 \quad$ Figure 7: Pumping tests in irrigation scenario as function of the solar radiation and water level in the well.

449 Another issue related to the operation of the studied PVWP system is the discrepancy 450 between crop water requirements and pumped water. The calculated monthly Alfalfa water 451 requirement varies a lot during the irrigation season registering its peak in June, as shown in 452 Fig 8. Comparing the modelled pumped water with the water demand, it is clear that the 453 PVWP system is unable to meet the irrigation water requirement for most of the irrigation 454 season. 


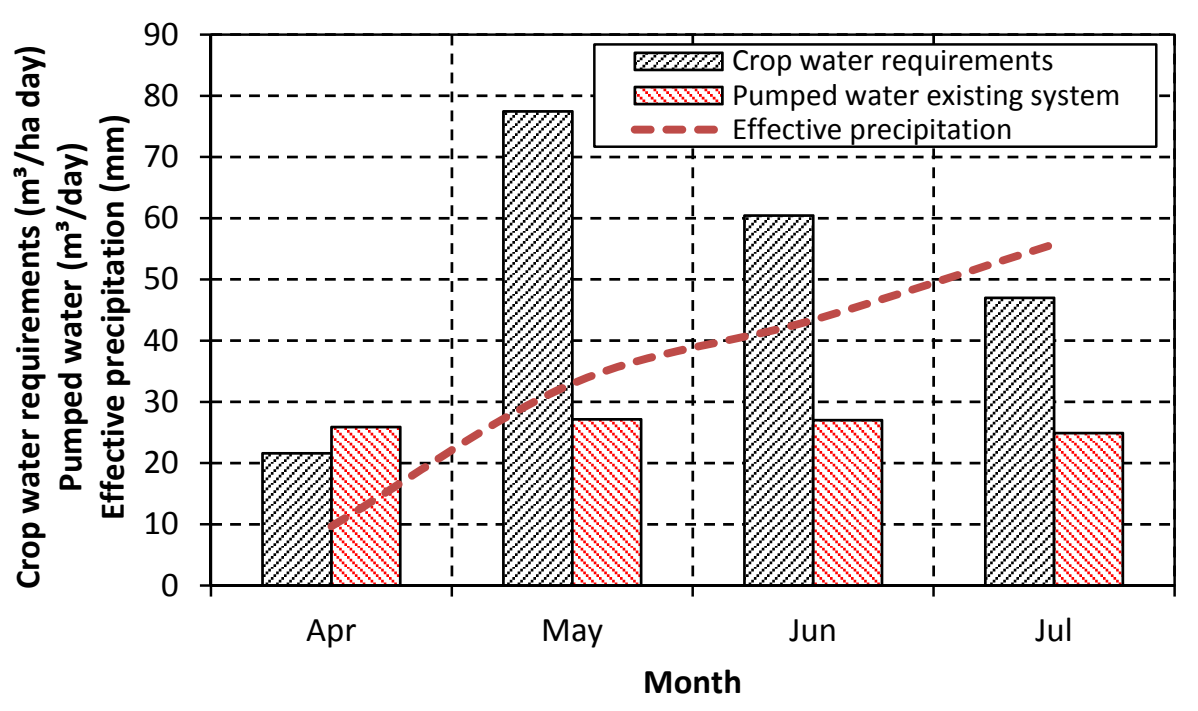

456

Figure 8: Alfalfa water demand, effective rainfall and pumped water from the existing PVWP system.

On one hand the PVWP system is oversized since the water level in the well reach the bottom;

but on the other hand the PVWP system is also undersized since it cannot supply the crop water need during the irrigation season. It has to be pointed out that the procedure adopted to design the existing PVWP system is unknown and not led by the authors of this paper.

\subsection{System optimization}

Using the approach given in section 2.6, the existing system has been optimized assuming a maximum hourly drawdown $s_{h}$ equal to $2.5 \mathrm{~m}$ that corresponds to the depth of the pump $h_{p}$ measured from the static water level. Table 5 summarizes the characteristic parameters (decision variables, operation failures, ICC, Alfalfa yield and $P B P$ ) for the existing and optimized PVWP system. 
Table 5: Existing and optimized PVWP characteristic parameters.

\begin{tabular}{|c|c|c|}
\hline Parameter & Existing system & Optimized system \\
\hline Number PV modules & 9 & 6 \\
\hline PVWP capacity $\left(\mathrm{kW}_{\mathrm{p}}\right)$ & 1.44 & 0.96 \\
\hline Pump capacity (kW) & 1.1 & 1.1 \\
\hline Tilt angle $\left({ }^{\circ}\right)$ & 42 & 10 \\
\hline Azimuth $\left({ }^{\circ}\right)$ & -36 & 8 \\
\hline ICC (US\$) & 4800 & 3900 \\
\hline Failures (time) & 350 & 0 \\
\hline$Y_{a}$ (tonne DM/ha) & 2.7 & 2.6 \\
\hline$P B P$ (years) & $\begin{array}{c}\text { > lifetime (forage } \\
\text { price } 207 \\
\$ / \text { tonne DM) }\end{array}$ & $\begin{array}{c}16 \text { (forage price } 207 \\
\text { \$/tonne DM) }\end{array}$ \\
\hline
\end{tabular}

472

473 The constraint due to the decline of the groundwater level reduces the PVWP capacity. As a

474 result, the PV size is decreased from $1.44 \mathrm{~kW}_{\mathrm{p}}$ to $0.96 \mathrm{~kW}$. In addition, the optimization of the

475 tilt and azimuth angle allows an increase of $10 \%$ in the PV power output during the irrigation

476 season compared to the existing orientation. The optimal tilt angle maximize the solar

477 irradiation harvested by the PV array during the irrigation period between April and July.

478 Figure 9 shows the effect of tilt angle on the annual revenues $R_{a n n}$. 


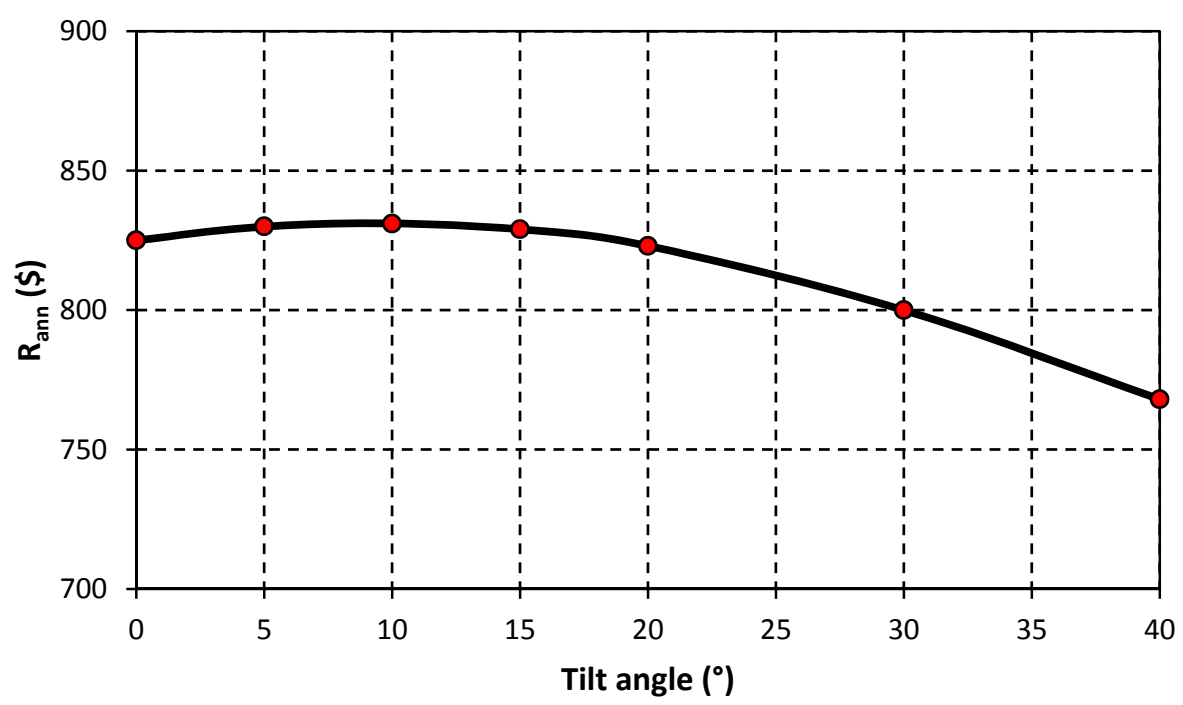

479

Figure 9: Effect of tilt angle on the annual revenues.

481 The optimal tilt angle causes an increase of the annual revenues of about $8 \%$ compared to the 482 tilt angle of the existing system. The ICC for the existing system is 4800 US\$. The main cost 483 item is represented by the PV modules accounting for $60 \%$ of the $I C C$, followed by engineering 484 and installation costs and inverter representing a share of $17 \%$ and $14 \%$, respectively. The ICC 485 for the optimized system is 3900 US\$, corresponding to a reduction in the ICC of $18.8 \%$ 486 compared to the current PVWP system. The reduction in investment cost is mainly due to the 487 less investment in PV modules and inverter and the resulting reduction in project 488 implementation costs.

489 In addition, the continuous operation is guaranteed during the whole irrigation season. 490 Compared to the 350 times that the existing system is shut down to avoid dry-up, the 491 optimized system never reaches the set level corresponding to the safety probe. Figure 10 492 shows the well water level trend for the optimized system during the irrigation season. 


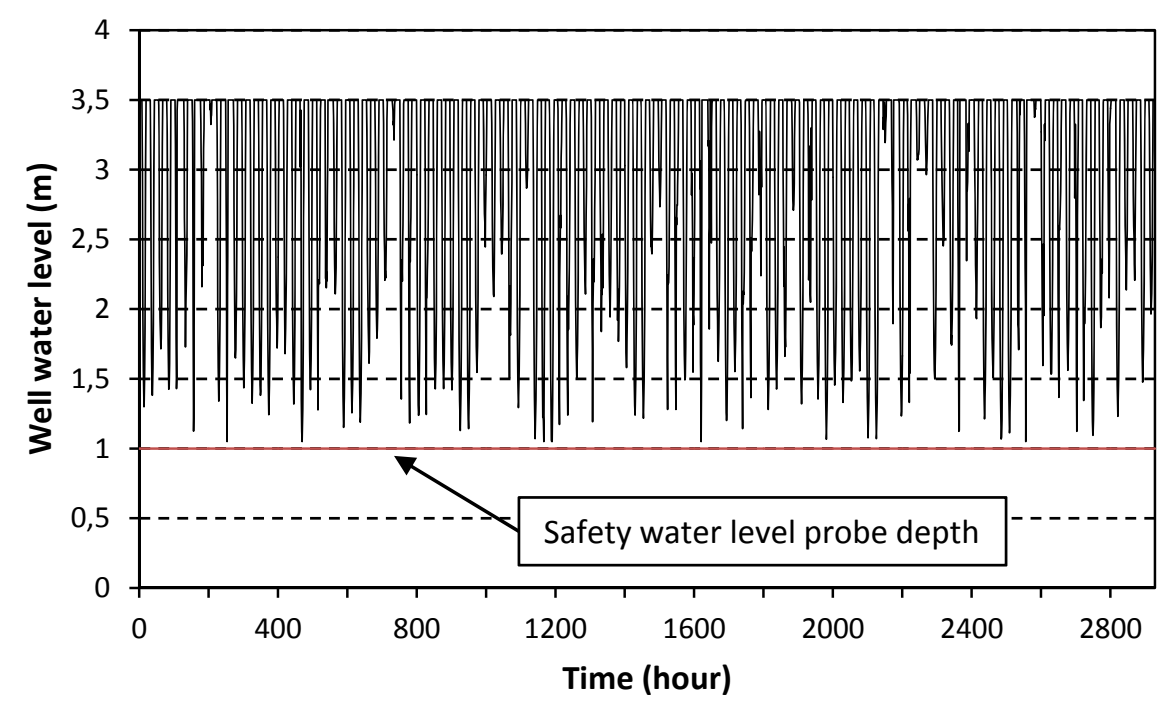

493

Figure 10: Well water level trend induced by the optimized system during the irrigation season.

496 To clearly illustrate the operation difference between the existing system and the optimal 497 system, dynamic simulations were conducted with a time step of 10 minutes for two days in 498 June. Figure 11 and 12 show the results of water flow and well water level. The optimal system operates between 8 am and $6 \mathrm{pm}$ reaching an hourly maximum flow rate of about $3.9 \mathrm{~m}^{3} / \mathrm{h}$

$500\left(0.65 \mathrm{~m}^{3} / 10 \mathrm{~min}\right)$ around $12 \mathrm{pm}$, producing a maximum drawdown of $2.3 \mathrm{~m}$ (equivalent to a minimum well water level of $1.2 \mathrm{~m}$ ) without reaching the water level probe (installed at 1

502 meter depth). On the contrary, the existing system is shut down in every hour after $12 \mathrm{pm}$. 


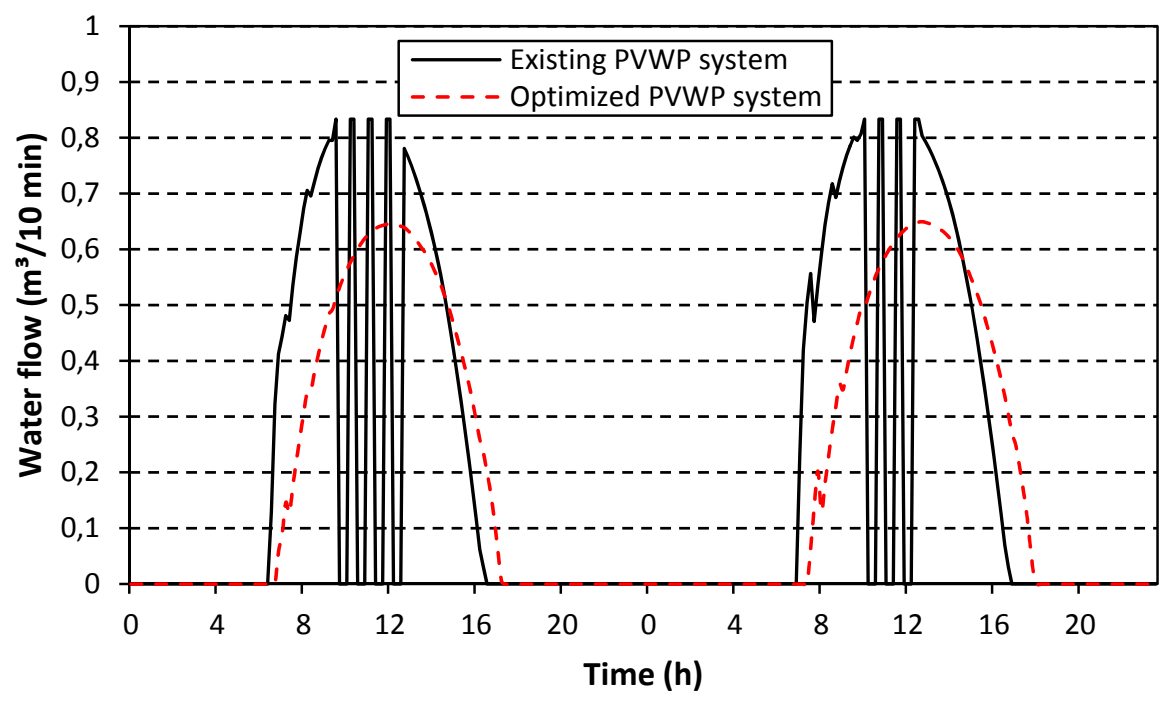

Figure 11: Simulations of the pumped water and well water level for the existing and optimized PVWP systems.

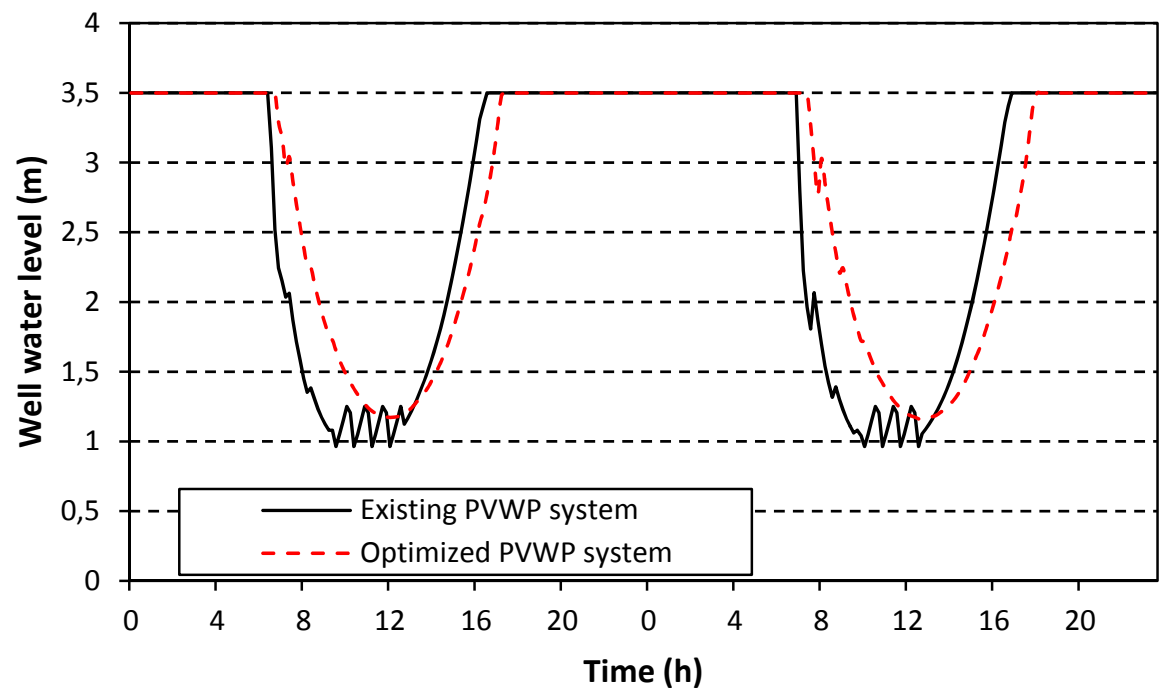

506

507 Figure 12: Simulations of the well water level for the existing and optimized PVWP systems.

508 Despite the decreased PV size, the effects of the pumped water on the crop yield in 509 insignificant due to the continuous shutdowns of the current installed PVWP system. The resulting annual crop yields at the end of the irrigation season are 2.7 and 2.6 tonne DM/ha 
511 for the existing system and the optimized system, respectively. Since the save from the ICC of

512 PV is much larger, the optimized system has a shorter PBP and the optimization makes the 513 PVWP system more suitable.

\section{$514 \quad 4.3$ Sensitivity study}

515 Sensitivity studies have been conducted to understand the effect of crop price and PV module

516 price, which are the key parameters for the economic analysis, on the optimization results.

517 The forage price has been set to vary between 150 and $300 \$ /$ tonne DM, whereas the PV

518 module price has been varied between 1 and $2 \$ / W_{p}$.

519 Figures 13 shows the effect of forage price on the optimal PVWP system capacity assuming a constant PV module price of $1.5 \$ / W_{p}$ together with the corresponding annual profit. With the increase of forage price, the annual profit rises; however, the forage price doesn't affect the optimal PVWP system size clearly. Similarly, there is no obvious impact on the optimal PVWP system capacity from the PV modules prices either, as depicted in Figure 14. The explanation

524 is that the groundwater constraint narrows the search of the optimal PVWP system capacity into a small range: between 0.25 to $0.96 \mathrm{~kW}_{\mathrm{p}}$ (the lower threshold corresponds to the minimum power peak to run the pumping system whereas the upper threshold corresponds to the maximum power peak to avoid an excessive drawdown). The search of the optimal PVWP system capacity is thus limited in a region where both the crop yield, and thus the annual revenues, and the PVWP system cost functions have a linear trend. Accordingly, the effects of PV module and forage price variation have a negligible effect in the search of the optimal system size. 


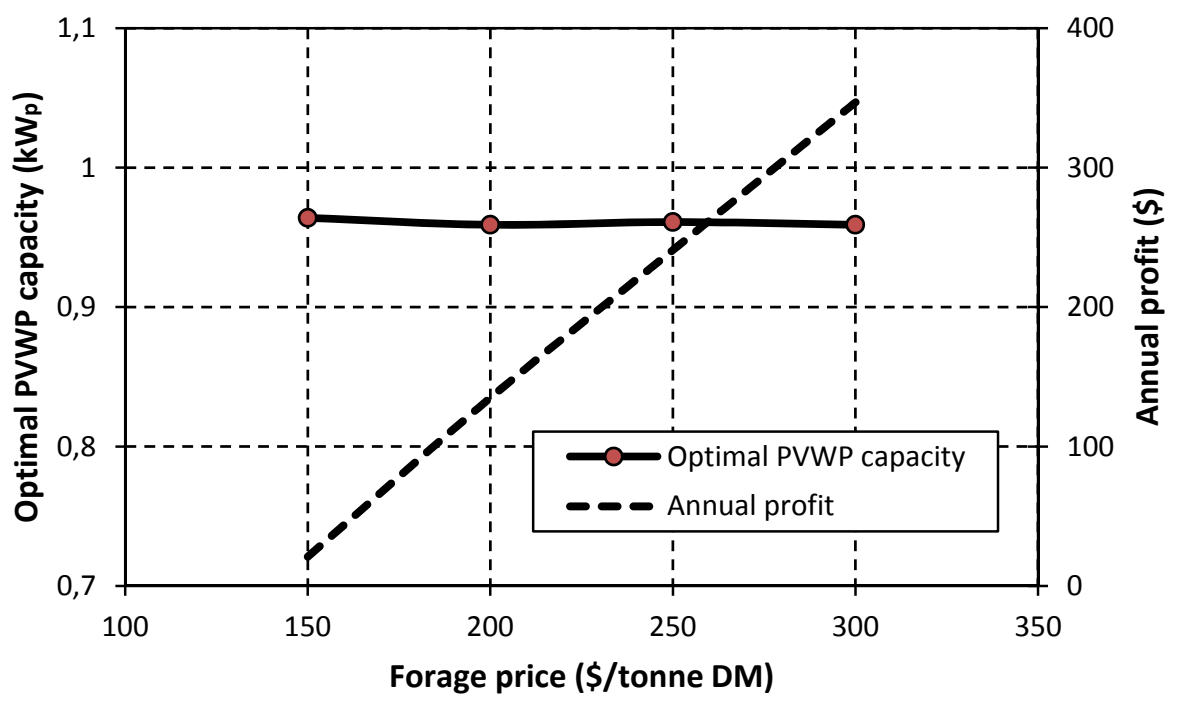

532

Figure 13: Effect of forage price on the optimal PVWP system size and annual revenues assuming a constant PV module price of $1.5 \$ / \mathrm{W}_{\mathrm{p}}$.

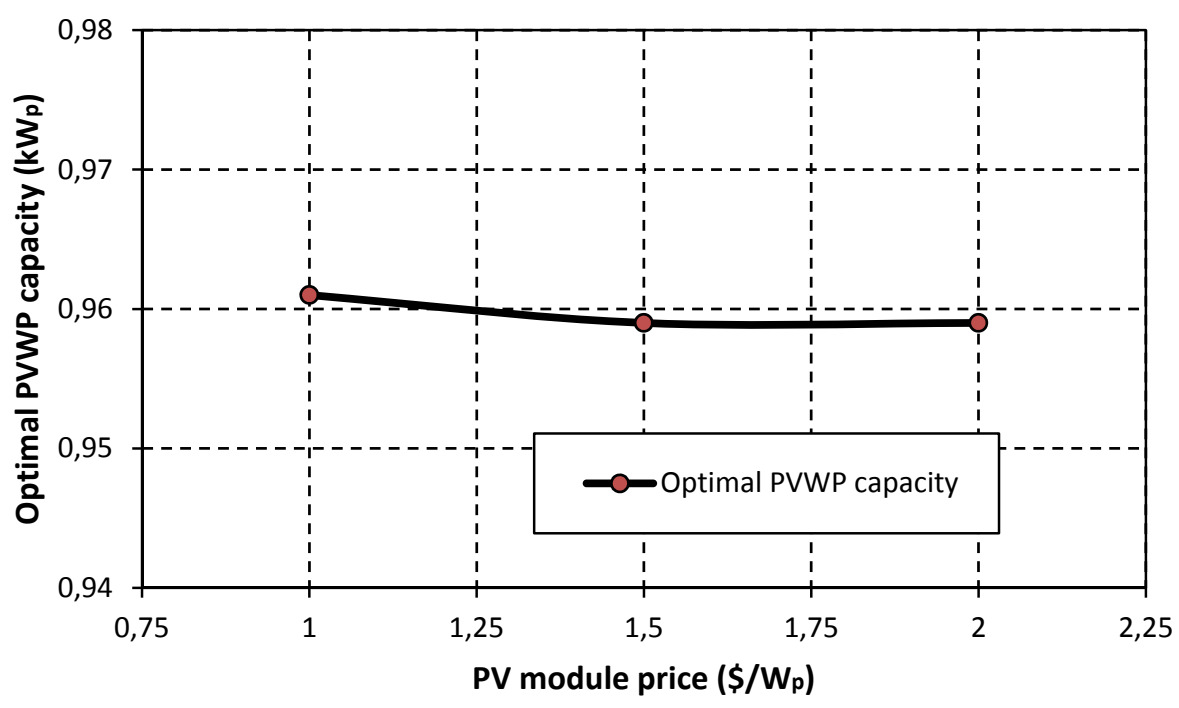

535

Figure 14: Effect of PV module price on the optimal PVWP system capacity assuming a constant forage price of $200 \$ /$ tonne DM.

As an example, Figure 15 shows the effect of the groundwater level constraint and PV module 

module price. Nevertheless, if the groundwater level constraint is disregarded, since the relationship between PVWP system capacity and crop yield is nonlinear, the price of PV modules has more obvious impacts on the optimal PVWP system capacity that maximizes the annual profit ( 2 and $2.2 \mathrm{~kW}$ for PV module price of 2.0 and $1.0 \$ / W_{p}$, respectively).

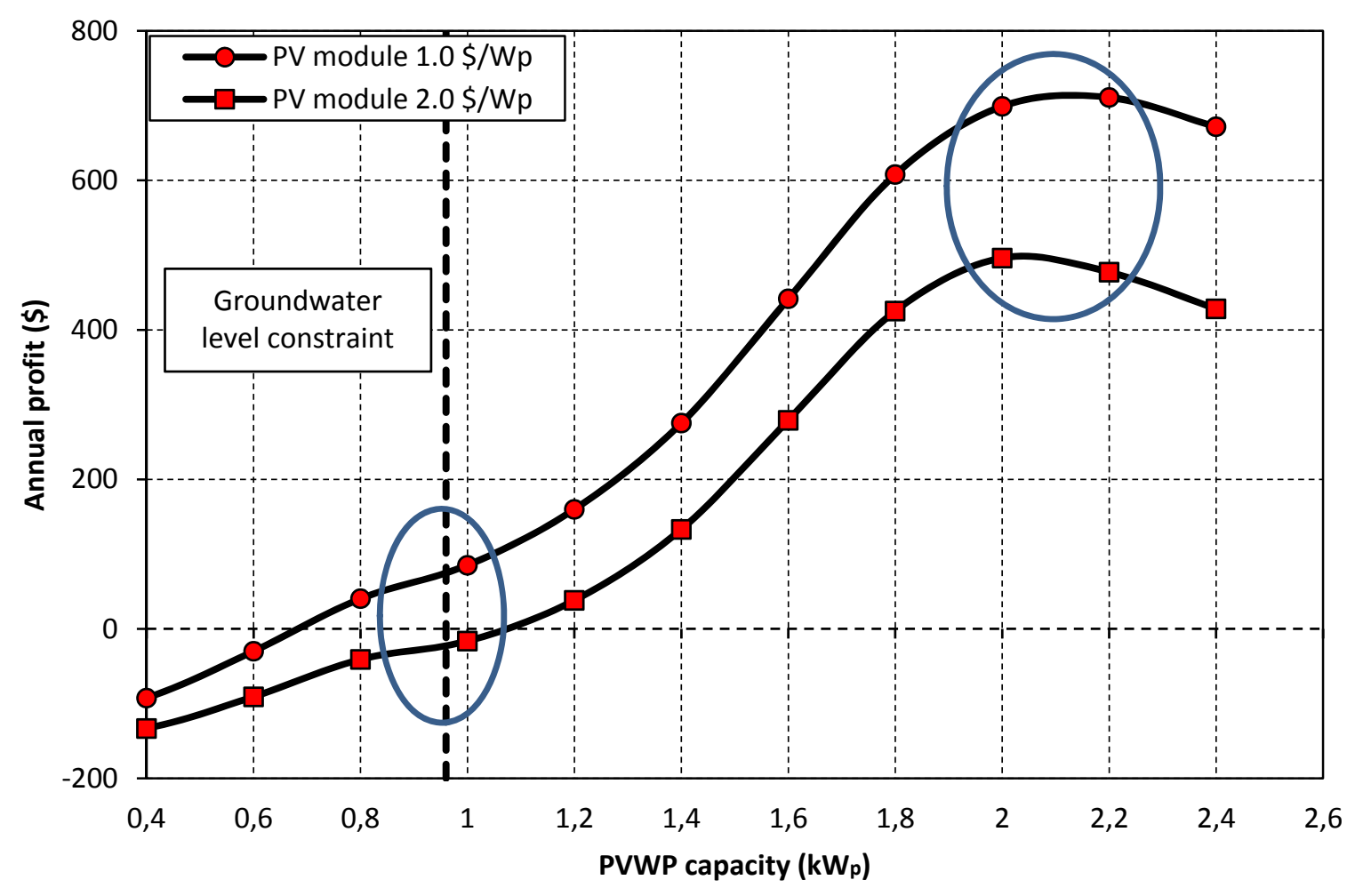

Figure 15: Effect of the groundwater level constraint on the optimal PVWP system capacity.

To identify those effects, the same sensitivity analyses have been conducted without the constraint of the groundwater level. Results are shown in Figure 16. The variation of PV modules and forage prices result in opposite trends. The increase of the forage price intends 
to raise the PVWP capacity; while the increase of PV price intends to reduce the capacity. The

553

554

555

556 optimization design can lead to significant economic benefits.

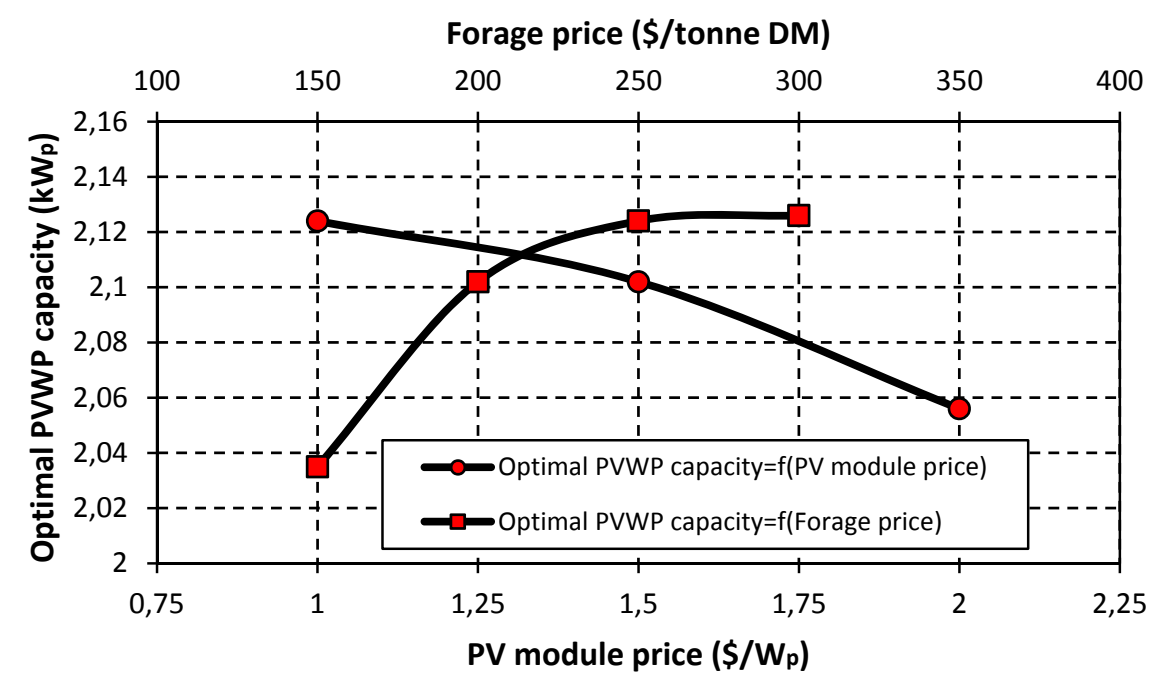

557

effect of the sensitive parameters variation on the PVWP system capacity is about $10 \%$. The results show the effectiveness and importance of considering the economic aspects into the optimization of PVWP systems for irrigation, especially for large applications where the

Figure 16: Effect of forage price and PV module price on the optimal PVWP system size assuming no groundwater response constraint.

The groundwater level constraint has played the key role in determining the optimal size of the PVWP system, assuming no system failures during the irrigation season (maximum reliability of the PVWP system in terms of operation continuity). The PV modules and forage price can affect the optimal PVWP system size but only if the drawdown is not a limiting factor. The optimization and simulation results show also how the groundwater level constraint is significant for ensuring high crop productivity and thus high PVWP system profitability. 


\section{Conclusions}

567

568

569

570

571

572

573

574

575

576

\section{7}

578

579

580

581

582

583

584

585

A new approach to optimize the photovoltaic water pumping (PVWP) system for irrigation has been proposed with the consideration of groundwater response and economic factors in this paper. Applying the proposed approach to an existing system shows a reduction in PV module size (from 1.44 down to $0.96 \mathrm{~kW}_{\mathrm{p}}$ ). This implies a decrease of $18.8 \%$ in the investment capital cost and therefore improve the economic feasibility of PVWP clearly. Even though the prices of crop and PV modules are the key parameters concerning the economic feasibility, according to the sensitivity study, they don't have clearly effects on the optimal system capacity if the ground water level is limited. However, if the groundwater level response to pumping does not represent a constraint, the increase of the forage price intends to raise the PVWP capacity; while the increase of PV price intend to reduce it.

\section{Acknowledgments}

The authors are grateful to the Swedish International Development Cooperation Agency (SIDA) and Swedish Agency for Economic and Regional Growth (Tillväxtverket) for the financial support.

\section{References}

[1] Longjun C., "UN Convention to combat desertification", Encyclopedia of Environmental Health, 2011, DOI: http://dx.doi.org/10.1016/B978-0-444-52272-6.00654-1.

[2] Yan J., Gao Z. Wang H. Liu J., “Qinghai pasture conservation using solar photovoltaic (PV)driven irrigation”, Asian Development Bank, Project Report, 2010. 
586

587

588

589

590

591

592

593

594

595

596

597

598

599

600

601

602

603

604

605

606

607

608

[3] Bouzidi B., Haddadi M., Belmokhtar O., "Assessment of a photovoltaic pumping system in the areas of the Algerian Sahara", Renewable and Sustainable Energy Reviews 13 (2009) 879886.

[4] Hrayshat E.S., Al-Soud M.S., "Potential of solar energy development for water pumping in Jordan”, Renewable Energy 29 (2004) 1393-1399.

[5] Bouzidi B., "Viability of solar or wind for water pumping systems in the Algerian Sahara regions - case study Adrar", Renewable and Sustainable Energy Reviews 15 (2011) 44364442.

[6] Ghoneim A.A., "Design optimization of photovoltaic powered water pumping systems", Energy Conversion and Management 47 (2006) 1449-1463.

[7] Benghanem M., Daffallah K.O., Alamri S.N., Joraid A.A., "Effect of pumping head on solar water pumping system", Energy Conversion and Management 77 (2014) 334-339.

[8] Mokeddem A., Midoun A., Kadri D., Hiadsi S., Raja I.A., “Performance of a directly-coupled PV water pumping system", Energy Conversion and Management 52 (2011) 3089-3095.

[9] Boutelhig A., Hadjarab A., Bakelli Y., "Comparison study to select an optimum photovoltaic pumping system (PVPS) configuration upon experimental performances data of two different dc pumps tested at Ghardaïa site", Energy Procedia 6 (2011) 769-776.

[10] Hamidat A., Benyoucef B., Hartani T., "Small-scale irrigation with photovoltaic water pumping system in Sahara regions", Renewable Energy 28 (2003) 1081-1096.

[11] Senol R., "An analysis of solar energy and irrigation systems in Turkey", Energy Policy 47 (2012) 478-486.

[12] Glasnovic Z., Margeta J., "A model for optimal sizing of photovoltaic irrigation water pumping systems", Solar Energy 81 (2007) 904-916. 

a solar PV pump based drip system for orchards", Renewable Energy 28 (2003) 385-396. 3451-3459.

614

[15] Campana P.E., Li H., Yan J., "Dynamic modelling of a PV pumping system with special consideration on water demand", Applied Energy 112 (2013) 635-645.

[16] Amer E.H., Younes M.A., "Estimating the monthly discharge of a photovoltaic water pumping system: Model verification", Energy Conversion and Management 47 (2006) 20922102.

[17] Hamidat A., Benyoucef B., "Mathematic models of photovoltaic motor-pump systems", Renewable Energy 33 (2008) 933-942.

621 [18] Luo Y., Sophocleous M., "Seasonal groundwater contribution to crop-water use assessed with lysimeter observations and model simulations", Journal of Hydrology 389 (2010) 325335.

[19] Campana P.E., Zhu Y., Brugiati E., Li H., Yan J., "PV water pumping for irrigation equipped with a novel control system for water savings", Proceedings of the $6^{\text {th }}$ International Conference on Applied Energy - ICAE2014. pumping systems for agricultural purposes: comparison of the potential benefits under three different incentive schemes", Proceedings of the $13^{\text {th }}$ World Renewable Energy Congress WREC XIII. 
631

632

633

634

635

636

637

638

639

640

641

642

643

644

645

646

647

648

649

650

651

652

[21] Xu H., Liu J., Qin D., Gao X., Yan J., "Feasibility analysis of solar irrigation system for pastures conservation in a demonstration area in Inner Mongolia", Applied Energy 112 (2013) 697-702.

[22] Yu Y., Liu J., Wang H., Liu M., “Assess the potential of solar irrigation systems for sustaining pasture lands in arid regions - A case study in Northwestern China", Applied Energy 88 (2011) $3176-3182$.

[23] Gao X., Liu J., Zhang J., Yan J., Bao S., Xua H., Qin T., "Feasibility evaluation of solar photovoltaic pumping irrigation system based on analysis of dynamic variation of groundwater table", Applied Energy 105 (2013) 182-193.

[24] Gao T., Zhang R., Zhang J., "Effect of Irrigation on Vegetation Production and Biodiversity on Grassland", Procedia Engineering 00 (2011) 000-0003-616.

[25] Olsson A., Campana P.E., Lind M., Yan J., "Potential for carbon sequestration and mitigation of climate change by irrigation of grasslands", Applied Energy 136 (2014) 11451154.

[26] Olsson A., Lind M., Yan J., "PV water pumping for increased resilience in dry land agriculture", Proceedings of the $6^{\text {th }}$ International Conference on Applied Energy - ICAE2014.

[27] Zhang C., Yan J., "Business model innovation on the photovoltaic water pumping systems for grassland and farmland conservation in China", Proceedings of the $6^{\text {th }}$ International Conference on Applied Energy - ICAE2014.

[28] Merei G., Berger C., Sauer D.U., "Optimization of an off-grid hybrid PV-Wind-Diesel system with different battery technologies using genetic algorithm", Solar Energy 97 (2013) 460-473. 
653

654

655

656

657

658

659

660

661

662

663

664

665

666

667

668

669

670

671

672

673

674

675

[29] Bean R., Wilhelm J., "U.S. Alfalfa Exports to China Continue Rapid Growth", USDA Foreign Agricultural Service-Global Agricultural Information Network Report, 2011.

[30] The World Bank. Available at: http://data.worldbank.org/indicator/FR.INR.RINR. Accessed: $1^{\text {st } J u l y ~} 2014$.

[31] Solartech. Available at: http://www.solartech.cn. Accessed: $1^{\text {st }}$ July 2014.

[32] Campana P.E., Olsson A., Li H., Yan J., "An economic analysis of photovoltaic water pumping irrigation systems", International Journal of Green Energy, (2015) (In press).

[33] SolveXL. Available at: http://www.solvexl.com/. Accessed: $1^{\text {st }}$ July 2014.

[34] Duffie J.A., Beckman W.A., "Solar engineering of thermal processes", 3rd ed. Wiley; 2006.

[35] CEEG. Available at: http://www.ceeg.cn/English/?lang=2. Accessed: $1^{\text {st }}$ July 2014.

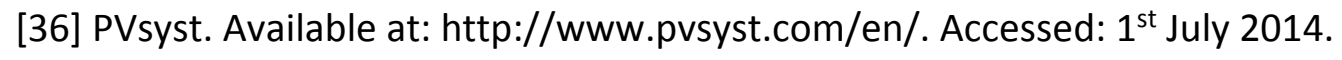

[37] Abella M.A., Lorenzo E., Chenlo F., "PV water pumping systems based on standard frequency converters", Prog. Photovolt: Res. Appl. 2003; 11:179-191 (DOI: 10.1002/pip.475). [38] Allen R.G., Pereira L.S., Raes D., Smith M., “Crop evapotranspiration. Guidelines for computing crop water requirements", FAO, 1998.

[39] Zhang, R. 2013. Personal communication. Institute of Water Resources for Pastoral Areas, Hohhot, China.

[40] Garg N.K., Dadhich S.M., "A proposed method to determine yield response factors of different crops under deficit irrigation using inverse formulation approach", Agricultural Water Management 137 (2014) 68-74.

[41] Igbadun H.E., Tarimo A.K.P.R., Salim B.A., Mahoo H.F., “Evaluation of selected crop water production functions for an irrigated maize crop", Agricultural water management 94 (2007) $1-10$. 
676 [42] Kruseman G.P., "Analysis and evaluation of pumping test data”, $2^{\text {nd }}$ ed., ILRI, 1994.

677 [43] Ospina J., Guarin N., Velez M., "Analytical solutions for confined aquifers with non678 constant pumping using computer algebra", Proceedings of the 2006 IASME/WSEAS Int. Conf. 679 on Water Resources, Hydraulics \& Hydrology, Chalkida, Greece, May 11-13, 2006 (pp7-12). 680 [44] Rasmussen T.C., Haborak K.G., Young M.H., "Estimating aquifer hydraulic properties using 681 sinusoidal pumping at the Savannah River site, South Carolina, USA", Hydrogeology Journal 682 (2003) 11:466-482.

683 [45] Zhang J., Liu J., Campana P.E., Zhang R., Yan J., Gao X., "Model of evapotranspiration and 684 groundwater level based on photovoltaic water pumping system", Applied Energy 136 (2014) $685 \quad 1132-1137$.

686 